\title{
Hedging Energy Revenues With Quantity-Triggered Puts
}

Zi "Nancy" Ning, Ph.D., Delaware State University, USA

Alan L. Tucker, Ph.D., Fudan University, Shanghai, China

\begin{abstract}
This paper offers a low-cost alternative for hedging energy producers' revenues. The hedging instrument exploits the less than perfectly positive correlation between energy output, or usage demand, and revenue. We provide a valuation formula for the instrument and demonstrate its ability to more effectively minimize a producer's value-at-risk when output uncertainty prevails.
\end{abstract}

Keywords: Energy Prices; Options; Hedging; Output Risk; Price Risk

\section{INTRODUCTION}

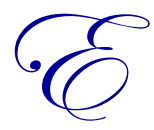

nergy producers hedge their future revenue streams using a wide variety of instruments and strategies including weather derivatives, swing contracts, virtual bidding, transmission congestion contracts, and financial transmission rights. There is a large body of literature that addresses the hedging of energy risk. Examples include Bessembinder and Lemmon (2002), Longstaff and Wang (2004), Deng and Oren (2006), Cartea and Villaplana (2008), and Willems and Morbee (2010). One of most popular revenue-hedging strategies used by energy producers is the purchase of plain-vanilla put options on the price of the energy product. In this paper we propose and analyze a lower-cost energy put option. The reduction in cost is achieved by a contract design that takes advantage of the less than perfectly positive correlation between local energy price and aggregate energy output, or energy demand, that characterizes most energy product markets. Because revenue is a function of price and output (usage demand), a hedging product that accommodates both elements likely presents advantages beyond a product that hedges price alone.

The product analyzed here is closely related to those addressed in Nam, Tucker and Wei (2005) and Ning and Tucker (2011). These authors focus on the hedging of general commodity output prices and agricultural import commodity prices, respectively. We employ the framework provided by these authors in order to propose and inspect a derivative security applicable to revenues from the production of energy products such as oil, electricity, and natural gas.

This paper is organized as follows: Section 2 introduces the general valuation formula for an outputtriggered energy put option. The valuation equation is further detailed in section 2 by specifying its convenience yield and volatility factors. Section 3 offers a simulation analysis designed to impart two key properties of the exotic energy option. Section 4 demonstrates the conditions under which a producer's value-at-risk may be more effectively minimized through the use of the exotic option vis-à-vis its plain-vanilla counterpart. A brief conclusion is presented in section 5 .

\section{OPTION PRICING MODEL}

Following Ahn et al (1999), Brown and Toft (2002), and especially Nam et al (2005) and Ning and Tucker (2011), we let energy prices, S, follow a two-factor process with a stochastic convenience yield, y, or:

$$
\begin{aligned}
& \mathrm{dS}=\left[\mu_{\mathrm{S}}(\mathrm{S}, \mathrm{t})-\mathrm{y}\right] \mathrm{Sdt}+\sigma_{\mathrm{S}}(\mathrm{t}) \mathrm{Sdz} \\
& \mathrm{dy}=\mu_{\mathrm{y}}(\mathrm{y}, \mathrm{t}) \mathrm{dt}+\sigma_{\mathrm{y}}(\mathrm{t}) \mathrm{ydz} \mathrm{y}_{\mathrm{y}} \\
& \mathrm{dQ}=\mu_{\mathrm{Q}}(\mathrm{t}) \mathrm{Qdt}+\sigma_{\mathrm{Q}}(\mathrm{t}) \mathrm{Qdz} z_{\mathrm{Q}}
\end{aligned}
$$


Where Q represents aggregate energy supply or output and where $E\left[\mathrm{dz}_{\mathrm{S}}, \mathrm{dz_{ \textrm {y } }}\right]=\rho_{\mathrm{Sy}} \mathrm{dt}, \mathrm{E}\left[\mathrm{dz_{ \textrm {S } }}, \mathrm{dz_{ \textrm {Q } }}\right]=\rho_{\mathrm{SQ}} \mathrm{dt}$, and $\mathrm{E}\left[\mathrm{dz}_{\mathrm{y}}, \mathrm{dz} \mathrm{Q}\right]=\rho_{\mathrm{yQ}} \mathrm{dt}$. $\mathrm{Q}$ is principally determined by usage demand, although supply shocks and other factors play a role. Equations (1), (2), and (3) represent a partial equilibrium model where price and output risk coexist, provided that their correlation is not plus one. In this representation future energy prices and future energy output are lognormally distributed, and the future convenience yield is normally distributed. ${ }^{1}$

Assuming that the energy product has a liquid spot market, the risk-neutral principle applies and the set of equations can be rewritten as follows:

$$
\begin{aligned}
& \mathrm{dS}=[\mathrm{r}-\mathrm{y}] \mathrm{Sdt}+\sigma_{\mathrm{S}}(\mathrm{t}) \mathrm{Sdz}_{\mathrm{S}}{ }^{*} \\
& \mathrm{dy}=\left[\mu_{\mathrm{y}}(\mathrm{y}, \mathrm{t})-\mathrm{R}(\mathrm{t})\right] \mathrm{dt}+\sigma_{\mathrm{y}}(\mathrm{t}) \mathrm{dz}_{\mathrm{y}}{ }^{*} \\
& \mathrm{dQ}=\mu_{\mathrm{Q}}(\mathrm{t}) \mathrm{Qdt}+\sigma_{\mathrm{Q}}(\mathrm{t}) \mathrm{Qdz} \mathrm{Q}_{\mathrm{Q}}{ }^{*}
\end{aligned}
$$

Where $\mathrm{r}$ is the riskless rate of interest (an assumed constant) and $\mathrm{R}(\mathrm{t})$ is the risk premium for the convenience yield. ${ }^{2}$

Now we introduce an option product whose payoff depends in part on whether or not future aggregate energy output, $\mathrm{Q}_{\mathrm{T}}$, is below a certain threshold, $\mathrm{Q}^{*}{ }^{3}$ An example is a put option on electricity whose payoff occurs if the future spot price of electricity is below the strike price and the aggregate electricity output is less than a prespecified wattage, which is presumably due to reduced usage demand, e.g., an unseasonably cool summer. This option would hedge a local energy producer's revenues due to low output (usage demand). This option's cost will be less than the cost of its counterpart plain-vanilla option, because the latter does not have a second payoff condition related to energy output (usage demand). Simply stated, energy providers are not particularly concerned about hedging price risk when usage demand is high; the hedging instrument proposed here only offers protection when usage demand is low, thereby reducing the cost of hedging revenue provided that energy price and usage demand are not perfectly correlated. ${ }^{4,5}$

$$
\text { We focus on puts triggered by } \mathrm{Q}_{\mathrm{T}}<\mathrm{Q}^{*}{ }^{6} \text { Here the option price, } \mathrm{P}_{1} \text {, is initially given by: }
$$

$$
\mathrm{P}_{1}=\mathrm{e}^{-\mathrm{r}(\mathrm{T}-\mathrm{t})} \mathrm{E}\left[\max \left(0, X-\mathrm{S}_{\mathrm{T}}\right) \mid \mathrm{Q}_{\mathrm{T}}<\mathrm{Q}^{*}\right]
$$

Where $\mathrm{E}$ is the risk-neutral expectations operator, and $\mathrm{X}$ represents the option's strike price. ${ }^{7}$ Given our previous assumptions regarding the stochastic processes of $S, Q$ and $y$, and that the option in equation (7) is European style, it can be demonstrated that its price is further given by: $:^{8}$

\footnotetext{
${ }^{1}$ The drift and diffusion coefficients will be identified later. For Q these coefficients will be time-dependent to accommodate the demand seasonality of certain energy products.

${ }^{2}$ A risk premium in the drift term for $\mathrm{Q}$ can be readily accommodated.

${ }^{3}$ In Nam et al (2005), a similar quantity-dependent put option is analyzed to hedge commodity output prices. In Ning and Tucker (2011), a quantity-dependent call option is analyzed to hedge agricultural import prices.

${ }^{4}$ The output-dependent option described here is a variant of a trigger option, which is most commonly traded in exotic currency option markets.

${ }^{5}$ The partial equilibrium representation used here is very general in the sense that it can accommodate various types of energy products exhibiting different convenience yields and the like. Indeed, the set up even permits options where the triggering factor is a proxy for local energy demand. For example, envision an option on electricity where the payoff is dependent on average local temperature (a proxy for local demand). This product would combine the features of an ordinary electricity option and a weather derivative.

${ }^{6}$ There are four types of output-triggered options, given the combinations of option types (calls and puts) and output triggers $\left(\mathrm{Q}_{\mathrm{T}}\right.$ $>\mathrm{Q}^{*}$ and $\mathrm{Q}_{\mathrm{T}}<\mathrm{Q}^{*}$ ). We focus on puts triggered by $\mathrm{Q}_{\mathrm{T}}<\mathrm{Q}^{*}$ because this type of option is the most relevant for energy producers, because it is likely that output reductions (lower usage demand) are associated with a drop in energy prices and, therefore, revenues.

${ }^{7}$ Letting $\mathrm{P}_{2}$ represent the price of a put whose payoff is triggered by $\mathrm{Q}_{\mathrm{T}}>\mathrm{Q}^{*}$, it can be readily demonstrated that the sum of $\mathrm{P}_{1}$ and $\mathrm{P}_{2}$ equals the price of an otherwise identical but plain-vanilla put option, thus implying by arbitrage that the price of each separate output-triggered option must be no greater than (and will almost surely be less than) the price of the plain-vanilla put. In other words, output-triggered options will be cheaper than their plain-vanilla counterparts.

${ }^{8}$ For analogous pricing formulas, see Nam et al (2005) and Ning and Tucker (2011).
} 


$$
\mathrm{P}_{1}=\mathrm{e}^{-\mathrm{r}(\mathrm{T}-\mathrm{t})}\left[\mathrm{X} \cdot \mathrm{N}\left(-\mathrm{d}_{1}+\Sigma_{\mathrm{S}} \rho_{\mathrm{SQ}}{ }^{*},-\mathrm{d}_{2}+\Sigma_{\mathrm{S}}, \rho_{\mathrm{SQ}}{ }^{*}\right)-\mathrm{F} \cdot \mathrm{N}\left(-\mathrm{d}_{1},-\mathrm{d}_{2}, \rho_{\mathrm{SQ}}{ }^{*}\right)\right]
$$

Where

$$
\begin{aligned}
& \mathrm{d}_{1}=\left[\ln \left(\mathrm{Q} / \mathrm{Q}^{*}\right)+\int \mu_{\mathrm{Q}}(\tau) \mathrm{d} \tau\right] / \Sigma_{\mathrm{Q}}+\Sigma_{\mathrm{S}} \rho_{\mathrm{SQ}}{ }^{*}-1 / 2 \Sigma_{\mathrm{Q}} \\
& \mathrm{d}_{2}=\left[\ln (\mathrm{F} / \mathrm{X})+\left(1 / 2 \Sigma_{\mathrm{S}}{ }^{2}\right)\right] / \Sigma_{\mathrm{S}} \\
& \Sigma_{\mathrm{S}}=\left\{\operatorname{var}\left[\int \mathrm{y}(\tau) \mathrm{d} \tau\right]+\operatorname{var}\left[\int \sigma_{\mathrm{S}}(\tau) \mathrm{dz}_{\mathrm{S}}{ }^{*}(\tau)\right]-2 \operatorname{cov}\left[\int \mathrm{y}(\tau) \mathrm{d} \tau, \int \sigma_{\mathrm{S}}(\tau) \mathrm{dz}_{\mathrm{S}}{ }^{*}(\tau)\right]\right\}^{1 / 2} \\
& \Sigma_{\mathrm{Q}}=\left\{\operatorname{var}\left[\int \sigma_{\mathrm{Q}}(\tau) \mathrm{dz}{ }_{\mathrm{Q}}^{*}(\tau)\right]\right\}^{1 / 2} \\
& \rho_{\mathrm{SQ}}=\left\{-\operatorname{cov}\left[\int \mathrm{y}(\tau) \mathrm{d} \tau, \int \sigma_{\mathrm{Q}}(\tau) \mathrm{dz} \mathrm{Q}_{\mathrm{Q}}{ }^{*}(\tau)\right]+\operatorname{cov}\left[\int \sigma_{\mathrm{S}}(\tau) \mathrm{dz}_{\mathrm{S}}{ }^{*}(\tau), \int \sigma_{\mathrm{Q}}(\tau) \mathrm{dz} \mathrm{Q}_{\mathrm{Q}}{ }^{*}(\tau)\right]\right\} /\left(\Sigma_{\mathrm{S}} \Sigma_{\mathrm{Q}}\right) \\
& \mathrm{F}=\mathrm{Se}^{\mathrm{H}} \\
& \mathrm{H}=\mathrm{r}(\mathrm{T}-\mathrm{t})-\mathrm{E}\left[\int \mathrm{y}(\tau) \mathrm{d} \tau\right]-1 / 2 \int\left(\sigma_{\mathrm{S}}\right)^{2}(\tau)(\mathrm{d} \tau)+1 / 2 \Sigma_{\mathrm{S}}{ }^{2}
\end{aligned}
$$

And where $\mathrm{F}$ is the energy commodity's forward price, $\tau=(\mathrm{T}-\mathrm{t})$, the limits of all integrals $\int \operatorname{are}$ from $\mathrm{t}$ to $\mathrm{T}$, var[ $\left[{ }^{\prime}\right]$ stands for variance, $\operatorname{cov}[\bullet]$ stands for covariance, and $\mathrm{N}(\bullet, \bullet, \rho)$ represents the cumulative joint probability distribution for two standard normal variables having a correlation coefficient $\rho .{ }^{9}$

Equation (8) is very general in the sense that, for now, the drift terms and diffusion coefficients are unspecified. A particular specification of these items follows shortly. On the other hand, equation (8) is only valid for the diffusion processes represented by equations (1) through (6). Allowing for non-normality, jumps in the stochastic processes, stochastic interest rates, or illiquidity in the spot marketplace would invalidate equation (8). However, we also remind the reader that, by arbitrage, the price of the output-triggered put must be no greater than the price of its counterpart plain-vanilla option (see footnote 8), and furthermore that another focus of this paper is the examination of the hedging effectiveness of the former option relative to the latter. Put another way, ordinary options and their pricing models are subject to the same concerns expressed previously in this paragraph.

Based on prior research, ${ }^{10}$ and following Nam et al (2005) and Ning and Tucker (2011), we let the convenience yield be mean reverting with a reversion speed $(\mathrm{k})$, reversion target $(\mathrm{m})$, diffusion coefficient [ $\left.\sigma_{\mathrm{y}}(\mathrm{t})\right]$, and market price of risk $[\mathrm{R}(\mathrm{t})]$ that are all constant. We also assume that for the energy product price and aggregate output, the diffusion coefficients $\sigma_{\mathrm{S}}(\mathrm{t})$ and $\sigma_{\mathrm{Q}}(\mathrm{t})$ are constant. Given these specifications, the risk-neutral processes are now represented by:

$$
\begin{aligned}
& \mathrm{dS}=[\mathrm{r}-\mathrm{y}] \mathrm{Sdt}+\sigma_{\mathrm{S}} \mathrm{Sdz}_{\mathrm{S}}{ }^{*} \\
& \mathrm{dy}=\mathrm{k}(\mathbf{m}-\mathrm{y}) \mathrm{dt}+\sigma_{\mathrm{y}} \mathrm{dz}_{\mathrm{y}}{ }^{*}{ }^{*} \\
& \mathrm{dQ}=\mu_{\mathrm{Q}}(\mathrm{t}) \mathrm{Qdt}+\sigma_{\mathrm{Q}} \mathrm{Qdz}_{\mathrm{Q}}{ }^{2}
\end{aligned}
$$

Where

$$
\begin{aligned}
& \mathbf{m}=\mathrm{m}-\mathrm{R} / \mathrm{k} \text {. And so the quantities in equation }(8) \text { become: } \\
& \begin{aligned}
\mathrm{H}= & {\left[(\mathbf{m}-\mathrm{y})+\left(\sigma_{\mathrm{S}} \sigma_{\mathrm{y}} \rho_{\mathrm{Sy}} / \mathrm{k}\right)+\left(\sigma_{\mathrm{y}}{ }^{2}\left(\mathrm{e}^{-\mathrm{k}(\mathrm{T}-\mathrm{t})}-3\right) / 4 \mathrm{k}^{2}\right)\right]\left[\left(1-\mathrm{e}^{-\mathrm{k}(\mathrm{T}-\mathrm{t})}\right) / \mathrm{k}\right] } \\
& +\left[(\mathrm{r}-\mathbf{m})+\left(\sigma_{\mathrm{y}}{ }^{2} / 2 \mathrm{k}^{2}\right)-\left(\sigma_{\mathrm{S}} \sigma_{\mathrm{y}} \rho_{\mathrm{Sy}} / \mathrm{k}\right)\right](\mathrm{T}-\mathrm{t})
\end{aligned} \\
& \begin{aligned}
\Sigma_{\mathrm{S}}{ }^{2} & =\left(\sigma_{\mathrm{y}}{ }^{2} / \mathrm{k}^{2}-\left(2 \sigma_{\mathrm{S}} \sigma_{\mathrm{y}} \rho_{\mathrm{Sy}} / \mathrm{k}\right)+\sigma_{\mathrm{S}}{ }^{2}\right)(\mathrm{T}-\mathrm{t})-\left[2\left(1-\mathrm{e}^{-\mathrm{k}(\mathrm{T}-\mathrm{t})}\right) / \mathrm{k}^{2}\right]\left[\sigma_{\mathrm{y}}{ }^{2} / \mathrm{k}-\sigma_{\mathrm{S}} \sigma_{\mathrm{y}} \rho_{\mathrm{Sy}}\right] \\
& +\left(\sigma_{\mathrm{y}}{ }^{2} / 2 \mathrm{k}^{3}\right)\left(1-\mathrm{e}^{-2 \mathrm{k}(\mathrm{T}-\mathrm{t})}\right)
\end{aligned} \\
& \begin{aligned}
\Sigma_{\mathrm{Q}}{ }^{2} & =\sigma_{\mathrm{Q}}{ }^{2}(\mathrm{~T}-\mathrm{t}) \\
\rho_{\mathrm{SQ}}{ }^{*} & =\left\{\sigma_{\mathrm{y}} \rho_{\mathrm{yQ}} /\left[\left[\mathrm{k}(\mathrm{T}-\mathrm{t})^{1 / 2}\right]\left[\left(1-\mathrm{e}^{-\mathrm{k}(\mathrm{T}-\mathrm{t})}\right) / \mathrm{k}-(\mathrm{T}-\mathrm{t})\right]\right]+\sigma_{\mathrm{S}} \rho_{\mathrm{SQ}}(\mathrm{T}-\mathrm{t})^{1 / 2}\right\} / \Sigma_{\mathrm{S}}
\end{aligned}
\end{aligned}
$$

Regarding $\mu_{\mathrm{Q}}(\mathrm{t})$, it can be specified for each distinct energy product. For example, it can be time-dependent so as to accommodate a product whose price is seasonal, such as electricity in the summer versus spring and fall.

\footnotetext{
${ }^{9}$ To obtain equation (8), one must first obtain the terminal values of the risk-neutral energy price, $\mathrm{S}_{\mathrm{T}}$, and aggregate output, $\mathrm{Q}_{\mathrm{T}}$. Then one must obtain the risk-neutral standard normal variables $\varepsilon_{\mathrm{S}}$ and $\varepsilon_{\mathrm{Q}}$ and their variances, covariance, and correlation, $\rho_{\mathrm{SQ}}{ }^{*}$. Then one must obtain the expression for the energy product's forward price, $\mathrm{F}$ (which is equivalent to its futures price since $\mathrm{r}$ is assumed constant). Very tedious algebra then leads to equation (8). A proof is this solution procedure is available upon request. See Nam et al (2005) and Ning and Tucker (2011) for similar analyses.

${ }^{10}$ Cf. Schwartz (1997), as related to the energy product oil.
} 


\section{NUMERICAL ANALYSIS}

There are many properties of our model, but for brevity we focus here on the two most interesting properties: (1) The effect on option price, $\mathrm{P}_{1}$, of the correlation between energy price and aggregate output, $\rho_{\mathrm{SQ}}$; and (2) the effect on option price of the correlation between convenience yield and aggregate output, $\rho_{\mathrm{yQ}}{ }^{11}$ Because most partial derivatives (comparative statics) are not available in closed form for our model, these properties are investigated using a numerical analysis. ${ }^{12}$

The assumed energy product is electricity. ${ }^{13}$ The base parameters for the simulation are $\mathrm{S}=\mathrm{X}=\$ 100.00$ (normalized to be per megawatt hour, $\mathrm{MWh}$ ), $\mathrm{T}-\mathrm{t}=1.00, \mathrm{Q}=100.00, \mathrm{Q}^{*}=122.14, \mathrm{r}=0.06, \mathrm{y}=0.10, \mathrm{k}=1.50, \mathbf{m}$ $=0.15, \mathrm{R}=0.20, \sigma_{\mathrm{S}}=0.30, \sigma_{\mathrm{y}}=0.40, \sigma_{\mathrm{Q}}=0.08, \mu_{\mathrm{Q}}=0.20, \rho_{\mathrm{SQ}}=0.50, \rho_{\mathrm{Sy}}=0.85$, and $\rho_{\mathrm{yQ}}=0.60 .{ }^{14}$

Table 1: Output-Triggered $\left(\mathbf{P}_{1}\right)$ and Counterpart Plain-Vanilla $(\mathbf{P})$ Put Prices

\begin{tabular}{llll}
\hline Variables & Values & $\mathbf{P}_{\mathbf{1}}$ & $\mathbf{P}$ \\
\cline { 2 - 3 } & & & \\
\hline$\rho_{\mathrm{SQ}}$ & 0.25 & $\$ 4.19$ & $\$ 8.89$ \\
& 0.50 & $\$ 5.60$ & $\$ 8.89$ \\
$\rho_{\mathrm{yQ}}$ & 0.75 & $\$ 6.33$ & $\$ 8.89$ \\
& 0.30 & $\$ 5.60$ & $\$ 8.89$ \\
& 0.60 & $\$ 4.93$ & $\$ 8.89$ \\
\hline
\end{tabular}

Notes: $\mathrm{P}_{1}$ is the price of the output-triggered put for the triggering condition $\mathrm{Q}_{\mathrm{T}}<\mathrm{Q}^{*}$, and $\mathrm{P}$ is the price of its counterpart plainvanilla put. Prices are denominated in U.S dollars. $\rho_{\mathrm{SQ}}$ represents the correlation between energy price and its aggregate output, and $\rho_{\mathrm{yQ}}$ represents the correlation between the energy commodity's convenience yield and aggregate output. The prices arise from a numerical analysis of equation (8) as specified in subsection 2.b. The base parameter values are $\mathrm{S}=\mathrm{X}=\$ 100.00$ (per $\mathrm{MWh}), \mathrm{T}-\mathrm{t}=1.00, \mathrm{Q}=100.00, \mathrm{Q}^{*}=122.14, \mathrm{r}=0.06, \mathrm{y}=0.10, \mathrm{k}=1.50, \mathbf{m}=0.15, \mathrm{R}=0.20, \sigma_{\mathrm{S}}=0.30, \sigma_{\mathrm{y}}=0.40, \sigma_{\mathrm{Q}}=0.08, \mu_{\mathrm{Q}}$ $=0.20, \rho_{\mathrm{SQ}}=0.50, \rho_{\mathrm{Sy}}=0.85$, and $\rho_{\mathrm{yQ}}=0.60$. The results indicated that the prices of the output-triggered options are lower than the prices of their plain-vanilla counterparts, and that the prices of output-triggered options decline as both the correlation between price and aggregate output and the correlation between convenience yield and aggregate output decline.

Table 1 presents the results of the numerical analysis. As expected, the value of the plain-vanilla put $(\mathrm{P})$ is invariant to both the correlation between price and aggregate output (usage demand) and the correlation between convenience yield and aggregate output (usage demand). Also as expected, the price of the output-triggered put $\left(\mathrm{P}_{1}\right)$ is lower than its counterpart plain-vanilla put. For instance, for the base case the plain-vanilla price is $\$ 8.89$ whereas the price for the exotic is it just $\$ 5.60$, a reduction of over 37 percent. ${ }^{15}$ Another anticipated result is evidenced upon the inspection of $\rho_{\mathrm{SQ}}$. As the correlation between price and output approaches 1, the value of the output-triggered put converges toward the value of its plain-vanilla counterpart, and vice versa. ${ }^{16}$ This result is what principally drives the advantage of the hedging instrument proposed here. If an energy producer is concerned about revenue, and that concern is occasioned by the prospect of reduced output presumably due to lower usage demand, then the producer can hedge its revenues at a lower cost by using the output-triggered put, provided that energy price and output are not perfectly correlated. By incorporating the triggering condition $\mathrm{Q}_{\mathrm{T}}<\mathrm{Q}^{*}$ directly into the hedging instrument's payoff per equations 7 and 8 , the upfront hedging cost is reduced.

\footnotetext{
${ }^{11}$ Results for other model properties are available upon request.

${ }^{12}$ Nam et al (2005) and Ning and Tucker (2011) employ a similar numerical investigation.

${ }^{13} \mathrm{We}$ assume here that the reader possesses an understanding of the basic operations and pricing fundamentals of the wholesale electricity marketplace.

${ }^{14}$ The output variable, $\mathrm{Q}$, is normalized to $100 \mathrm{MWh}$ 's. The critical output value, $\mathrm{Q}^{*}$, is set at the forward level, i.e., $\mathrm{Q}^{*}=$ $\mathrm{Qe} \hat{\wedge} \mu_{\mathrm{Q}}(\mathrm{T}-\mathrm{t})=122.14 \mathrm{MWh}$. The correlations are established to insure a positive correlation between price and output (or usage demand), a positive correlation between convenience yield and price, and thus a positive correlation between convenience yield and output (or usage demand). See Nam et al (2005).

${ }^{15}$ While not shown, the base-case price of the output-triggered put where the triggering condition is $\mathrm{Q}_{\mathrm{T}}>\mathrm{Q}^{*}$ is $\$ 3.29$. Thus the sum of the two output-triggered puts $(\$ 5.60+\$ 3.29)$ is indeed equal to the price of the plain-vanilla put $(\$ 8.89)$. See footnote 8 .

${ }^{16}$ In other words, we are back to a single state-variable when correlation is 1 . This result obtains over a range of option strike prices. A similar finding is reported by Nam et al (2005) and Ning and Tucker (2011).
} 
Focusing now on the correlation between the convenience yield and aggregate output, Table 1 illustrates that a higher positive correlation leads to a lower value of the output-triggered put. For instance, the outputtriggered put price drops from $\$ 6.33$ to $\$ 4.93$ when $\rho_{\mathrm{yQ}}$ increases from 0.30 to 0.90 . This result reflects the economic intuition that a higher positive value of $\rho_{\mathrm{yQ}}$ means that greater energy output is probably accompanied by a higher convenience yield (reflecting periods of high usage demand), a higher energy price, and a lower expected put option payoff, which translates to a savings (in the form of a lower option cost) available to the hedger who employs a quantity-triggered put option rather than its plain-vanilla counterpart. ${ }^{17}$

\section{MINIMIZING VALUE-AT-RISK}

In the spirit of Sakong et al (1993), Ahn et al (1999), Brown and Toft (2002), and especially Nam et al (2005) and Ning and Tucker (2011), we investigate the optimal use of the option represented by equation (8) for hedging energy producer revenue risk. More specifically, we examine the optimal choice of strike price for this put, i.e., the strike price that minimizes the producer's value-at-risk (VaR), and investigate if the use of this put is more effective than the use of its plain-vanilla counterpart. Put another way, we address the question of whether the output-triggered put or its plain-vanilla counterpart is more effective in reducing the energy producer's VaR, given the same hedging cost, confidence level, and hedging horizon. Because the output-triggered put can hedge both price and output (usage demand) risk, whereas its plain-vanilla counterpart only can hedge price risk per se, we anticipate that the former option will be a superior hedging product when output (usage demand) risk is high.

Let $\mathrm{Q}_{\mathrm{i}}$ refer to the output of energy product produced by a particular energy provider $\mathrm{i}$, and let $\mathrm{Q}_{\mathrm{i}}$ follow $\mathrm{a}$ lognormal diffusion process with constant volatility so that in a risk-neutral setting we have:

$$
\mathrm{dQ}_{\mathrm{i}}=\mu_{\mathrm{Qi}}(\mathrm{t}) \mathrm{Q}_{\mathrm{i}} \mathrm{dt}+\sigma_{\mathrm{Qi}_{\mathrm{i}}} \mathrm{Q}_{\mathrm{i}} \mathrm{dz}_{\mathrm{Qi}}{ }^{*}
$$

The relevant correlations are $\mathrm{E}\left[\mathrm{dz}_{\mathrm{S}}, \mathrm{dz}_{\mathrm{Qi}}\right]=\rho_{\mathrm{SQi}} \mathrm{dt}, \mathrm{E}\left[\mathrm{dz}_{\mathrm{y}}, \mathrm{dz}_{\mathrm{Qi}}\right]=\rho_{\mathrm{yQi}} \mathrm{dt}$, and $\mathrm{E}\left[\mathrm{dz}_{\mathrm{Qi}}, \mathrm{dz} \mathrm{z}_{\mathrm{Q}}\right]=\rho_{\mathrm{QiQ}} \mathrm{dt}^{18}$. The product of price times output, $\mathrm{R}=\mathrm{SQ}_{\mathrm{i}}$, is the total revenue to the producer and is thus the risk variable to minimize. So the initial VaR is given by: ${ }^{19}$

$$
\mathrm{VaR}=\mathrm{f}_{\mathrm{R}}-\mathrm{Re}^{\theta(\alpha)}
$$

Where $\mathrm{Re}^{\theta(\alpha)}$ is the point at the $\alpha$ percentile of the tail distribution of $\mathrm{R}_{\mathrm{T}}$ (in the real world), and $\mathrm{f}_{\mathrm{R}}$ is the forward level of $R$ (in a risk-neutral world). Using Ito's lemma, we have $f_{R}=E\left(R_{T}\right) \equiv \operatorname{Re}^{\wedge}\left(H_{R}\right)$ where: ${ }^{20}$

$$
\begin{aligned}
& \theta(\alpha)=\left(\mu_{\mathrm{S}}+\mu_{\mathrm{Qi}}-\mathrm{m}\right)(\mathrm{T}-\mathrm{t})-(\mathrm{y}-\mathrm{m})\left[\left(1-\mathrm{e}^{-\mathrm{k}(\mathrm{T}-\mathrm{t})}\right) / \mathrm{k}\right]-(1 / 2)\left(\sigma_{\mathrm{S}}{ }^{2}+{\sigma_{\mathrm{Qi}}}^{2}\right)(\mathrm{T}-\mathrm{t})+\mathrm{z}(\alpha) \Sigma_{\mathrm{R}} \\
& \mathrm{H}_{\mathrm{R}}=\left[\mu_{\mathrm{Qi}}+\mathrm{r}+\sigma_{\mathrm{S}} \sigma_{\mathrm{Qi}} \rho_{\mathrm{SQi}}-\mathbf{m}-\left(\sigma_{\mathrm{Qi}} \sigma_{\mathrm{y}} \rho_{\mathrm{yQi}} / \mathrm{k}\right)+\left(\sigma_{\mathrm{y}}{ }^{2} / 2 \mathrm{k}^{2}\right)-\left(\sigma_{\mathrm{S}} \sigma_{\mathrm{y}} \rho_{\mathrm{SY}} / \mathrm{k}\right)\right](\mathrm{T}-\mathrm{t}) \\
& +\left[\left(\mathbf{m}-\mathrm{y}-\left(\sigma_{\mathrm{y}}{ }^{2} / \mathrm{k}^{2}\right)+\left(\sigma_{\mathrm{S}} \sigma_{\mathrm{y}} \rho_{\mathrm{Sy}} / \mathrm{k}\right)+\left(\sigma_{\mathrm{Qi}} \sigma_{\mathrm{y}} \rho_{\mathrm{yQi}} / \mathrm{k}\right)\right]\left[\left(1-\mathrm{e}^{-k(\mathrm{~T}-\mathrm{t})}\right) / \mathrm{k}\right]\right. \\
& +\left[\sigma_{\mathrm{y}}^{2} / 4 \mathrm{k}^{3}\right]\left[\left(1-\mathrm{e}^{-2 \mathrm{k}(\mathrm{T}-\mathrm{t})}\right)\right] \\
& \Sigma_{\mathrm{R}}^{2}=\left[\left(\sigma_{\mathrm{y}}{ }^{2} / 2 \mathrm{k}^{2}\right)-\left(\sigma_{\mathrm{Qi}} \sigma_{\mathrm{y}} \rho_{\mathrm{yQi}} / \mathrm{k}\right)-\left(\sigma_{\mathrm{S}} \sigma_{\mathrm{y}} \rho_{\mathrm{S} /} / \mathrm{k}\right)+1 / 2\left(\sigma_{\mathrm{S}}{ }^{2}+\sigma_{\mathrm{Qi}}{ }^{2}+2 \sigma_{\mathrm{S}} \sigma_{\mathrm{Qi}} \rho_{\mathrm{SQi}}\right)\right](\mathrm{T}-\mathrm{t}) \\
& +\left[\left(\sigma_{\mathrm{S}} \sigma_{\mathrm{y}} \rho_{\mathrm{Sy}} / \mathrm{k}\right)+\left(\sigma_{\mathrm{Q}_{\mathrm{i}}} \sigma_{\mathrm{y}} \rho_{\mathrm{yQi}} / \mathrm{k}\right)-\left(\sigma_{\mathrm{y}}^{2} / \mathrm{k}^{2}\right)\right]\left[\left(1-\mathrm{e}^{-\mathrm{k}(\mathrm{T}-\mathrm{t})}\right) / \mathrm{k}\right] \\
& +\left[\sigma_{\mathrm{y}}^{2} / 4 \mathrm{k}^{3}\right]\left[\left(1-\mathrm{e}^{-2 \mathrm{k}(\mathrm{T}-\mathrm{t})}\right)\right]
\end{aligned}
$$

Now let us introduce the hedging instrument (the output-triggered put option) into the VaR expression. Letting $\mathrm{h}(0<\mathrm{h}<1)$ be the hedge ratio, i.e., the fraction of the put for each unit of the energy commodity produced (in order to meet usage demand), the producer's VaR is given by:

$$
\mathrm{VaR}=\mathrm{f}_{\mathrm{R}}-\mathrm{Re}^{\theta(\alpha)}+\mathrm{Q}_{\mathrm{i}} \mathrm{h}\left(\mathrm{P}_{1}\right) \mathrm{e}^{\mathrm{r}(\mathrm{T}-\mathrm{t})}-\mathrm{Q}_{\mathrm{i}} \mathrm{h}\left[\mathrm{X}-\mathrm{Re}^{\theta(\alpha)} / \mathrm{Q}_{\mathrm{iT}}\right], \text { if } \mathrm{Q}_{\mathrm{T}}<\mathrm{Q}^{*}
$$

\footnotetext{
${ }^{17}$ A similar result is reported by Nam et al (2005).

${ }^{18}$ The "i" terms should be read as subscripts of the Q terms in equation (12) and its relevant correlations. The same reading should occur in the equations that follow.

${ }^{19}$ The VaR here is "initial" in the sense we have yet to introduce the hedging instrument into the minimization problem.

${ }^{20}$ Here we assume that the drifts of the energy price and producer i's quantity are constant, and that $\mathrm{z}(\alpha)$ is a standard normal variable corresponding to the $\alpha$ percentile of the distribution, e.g., $z(0.025)=-1.96$.
}

(C) 2013 The Clute Institute http://www.cluteinstitute.com/ 
Integrating over the two quantity variables conditional on the $\alpha$ percentile of the distribution for $\mathrm{R}_{\mathrm{T}}$, and following Ahn et al (1999) and especially Nam et al (2005), the energy producer's optimization problem can now be expressed as follows:

$$
\begin{aligned}
& \text { Min } \operatorname{VaR}=f_{R}-\operatorname{Re}^{\theta(\alpha)}+Q_{i} h\left(P_{1}\right) e^{r(T-t)}-Q_{i} h\left\{\left[X\left(\Omega_{2} / \Omega_{1}\right)\right]-\left[\operatorname{Se}^{\wedge}\left[(\theta \alpha)-\left(\mu_{Q}-\sigma_{Q}^{2}\right)(T-t)\right]\left(\Omega_{3} / \Omega_{1}\right]\right\}\right. \\
& \text { s.t. } B=Q_{i} h\left(P_{1}\right)
\end{aligned}
$$

Where the minimization is over $(\mathrm{h}, \mathrm{X}), \mathrm{B}$ is the total hedging cost, and where

$$
\begin{aligned}
& \Omega_{1}=\mathrm{N}\left(\mathrm{d}_{2}{ }^{\prime}-\Sigma_{\mathrm{R}}\right) \\
& \Omega_{2}=\mathrm{N}\left(\mathrm{d}_{1},-\Sigma_{\mathrm{R}} \rho_{\mathrm{RQ}}{ }^{*}, \mathrm{~d}_{2}{ }^{\prime}-\Sigma_{\mathrm{R}}, \rho_{\mathrm{RQ}}{ }^{*}\right) \\
& \Omega_{3}=\mathrm{N}\left[\mathrm{d}_{1}-\Sigma_{\mathrm{R}} \rho_{\mathrm{RQ}}{ }^{*}-\left(\sigma_{\mathrm{Q}} \sigma_{\mathrm{Qi}} \rho_{\mathrm{QQi}}(\mathrm{T}-\mathrm{t}) / \Sigma_{\mathrm{Q}}\right), \mathrm{d}_{2}{ }^{*}-\Sigma_{\mathrm{R}}-\left(\sigma_{\mathrm{RQi}} / \Sigma_{\mathrm{R}}\right), \rho_{\mathrm{RQ}}{ }^{*}\right] \\
& \mathrm{d}_{1}=\left[\ln \left(\mathrm{Q} / \mathrm{Q}^{*}\right)+\mu_{\mathrm{Q}}(\mathrm{T}-\mathrm{t})\right] / \Sigma_{\mathrm{Q}}+\Sigma_{\mathrm{R}} \rho_{\mathrm{RQ}}{ }^{*}-1 / 2 \Sigma_{\mathrm{Q}} \\
& \mathrm{d}_{2}=\left[\ln \left[\mathrm{f}_{\mathrm{R}} /\left(\operatorname{Re}^{\theta(\alpha)}\right)\right]+\left(1 / 2 \Sigma_{\mathrm{R}}{ }^{2}\right)\right] / \Sigma_{\mathrm{R}} \\
& \sigma_{\mathrm{RQi}}=\left(\sigma_{\mathrm{y}} \sigma_{\mathrm{Qi}} \rho_{\mathrm{yQi}} / \mathrm{k}^{2}\right)\left(1-\mathrm{e}^{-\mathrm{k}(\mathrm{T}-\mathrm{t})}\right)+\left[\left(\sigma_{\mathrm{Qi}}{ }^{2}+\sigma_{\mathrm{S}} \sigma_{\mathrm{Qi}} \rho_{\mathrm{SQi}}-\left(\sigma_{\mathrm{y}} \sigma_{\mathrm{Qi}} \rho_{\mathrm{yQi}} / \mathrm{k}\right)\right](\mathrm{T}-\mathrm{t})\right. \\
& \rho_{\mathrm{R}, \mathrm{Q}}=\left\{\sigma_{\mathrm{y}} \sigma_{\mathrm{Q}} \rho_{\mathrm{yQ}}\left(1-\mathrm{e}^{-\mathrm{k}(\mathrm{T}-\mathrm{t})}\right) / \mathrm{k}^{2}+\left(\sigma_{\mathrm{Q}} \sigma_{\mathrm{Qi}} \rho_{\mathrm{QQi}}+\sigma_{\mathrm{S}} \sigma_{\mathrm{Q}} \rho_{\mathrm{SQ}}-\left(\sigma_{\mathrm{y}} \sigma_{\mathrm{Q}} \rho_{\mathrm{yQ}}\right) / \mathrm{k}\right)(\mathrm{T}-\mathrm{t})\right\} / \Sigma_{\mathrm{Q}} \Sigma_{\mathrm{R}} \\
& \mathrm{f}_{\mathrm{R}}=\operatorname{Re}^{\wedge}\left(\mathrm{H}_{\mathrm{R}}\right) \\
& \mathrm{H}_{\mathrm{R}}{ }^{\prime}=\left[\mu_{\mathrm{Qi}}+\mu_{\mathrm{S}}+\sigma_{\mathrm{S}} \sigma_{\mathrm{Qi}} \rho_{\mathrm{SQi}}-\mathrm{m}-\left(\sigma_{\mathrm{Qi}} \sigma_{\mathrm{y}} \rho_{\mathrm{yQi}} \mathrm{k}\right)+\left(\sigma_{\mathrm{y}}{ }^{2} / 2 \mathrm{k}^{2}\right)-\left(\sigma_{\mathrm{S}} \sigma_{\mathrm{y}} \rho_{\mathrm{Sy}} / \mathrm{k}\right)\right](\mathrm{T}-\mathrm{t})+\left[\left(\mathrm{m}-\mathrm{y}-\left(\sigma_{\mathrm{y}}{ }^{2} / \mathrm{k}^{2}\right)\right.\right. \\
& \left.+\left(\sigma_{\mathrm{S}} \sigma_{\mathrm{y}} \rho_{\mathrm{Sy}} / \mathrm{k}\right)+\left(\sigma_{\mathrm{Qi}} \sigma_{\mathrm{y}} \rho_{\mathrm{yQi}} / \mathrm{k}\right)\right]\left[\left(1-\mathrm{e}^{\mathrm{k}(\mathrm{T}-\mathrm{t})}\right) / \mathrm{k}\right]+\left[\sigma_{\mathrm{y}}{ }^{2} / 4 \mathrm{k}^{3}\right]\left[\left(1-\mathrm{e}^{-2 \mathrm{k}(\mathrm{T}-\mathrm{t})}\right)\right]
\end{aligned}
$$

Consistent with Nam et al (2005) and Ning and Tucker (2011), a comparison of equations (13) and (14) or (15) illustrates that when the option is introduced into the VaR minimization procedure, the VaR increases by the terminal value of the option, i.e., its initial cost carried forward at the riskless rate, r. However, the VaR reduces by the option's payoff (conditioned on the payoff occurring) times the hedge ratio, $h$, this product times the output of the energy commodity, $\mathrm{Q}_{\mathrm{i}}$. When the triggering output level, $\mathrm{Q}^{*}$, is set to infinity, the output-triggered put option is merely a plain-vanilla put. Equation (14) or (15) therefore provides us with insight into which option will present the more effective revenue hedge: Replacing the plain-vanilla put with the output-triggered put will on one hand increase the hedge ratio, h, due to the lower cost of the latter option; on the other hand, the expected payoff to the energy producer/hedger is also lower due to it now being conditioned on $\mathrm{Q}_{\mathrm{T}}<\mathrm{Q}^{*}$. Still, energy producers are generally unconcerned with hedging price risk when output (usage demand) is high. The output-triggered put will present the superior hedging instrument when its advantage (lower cost and therefore greater hedge ratio) outweighs its disadvantage (the added payoff-triggering requirement that $\mathrm{Q}_{\mathrm{T}}<\mathrm{Q}^{*}$ ). Under what condition(s) will the advantage dominate? ? $^{21}$

It is not possible to analytically solve the formidable optimization problem presented by equation (15). So, following Nam et al (2005) and Ning and Tucker (2011), we utilize numerical procedures and examine how the optimal strike price, $\mathrm{X}^{*}$, varies across different parameter values. More specifically, we numerically examine the VaR's first-order condition with respect to $X^{*}$ while using the same base parameter values reported previously in section 3 , as well as the following additional parameter values: $\mu_{\mathrm{S}}=0.20, \alpha=0.025, \mu_{\mathrm{Qi}}=0.20, \sigma_{\mathrm{Qi}}=0.10, \rho_{\mathrm{SQi}}=$ $0.40, \rho_{\mathrm{yQi}}=0.50, \rho_{\mathrm{QQi}}=0.60$, and $\mathrm{Q}_{\mathrm{i}}=1.0$.

We examine the VaR's first-order condition with respect to $\mathrm{X}^{*}$ in two cases, one where the output-triggered put option is used in the optimization and the other where its plain-vanilla counterpart is employed. ${ }^{22}$ Upon changing the various parameter values and comparing the resulting optimal exercise prices under the two different hedging instruments, we draw the following general inference from the numerical analysis: The output-triggered option is more effective in minimizing the local energy producer's VaR when (a) the energy commodity's price volatility is low, (b) the correlation between energy price and aggregate output (usage demand) is low, and (c) the correlation between the local producer's output and aggregate output is low coupled with high volatility in either output variable. These findings are intuitive. The plain-vanilla option only can hedge energy price risk whereas the

\footnotetext{
${ }^{21}$ A closer inspection of equation (15) reveals another interesting result, namely: If we ignore the triggering condition $\mathrm{Q}^{*}$, set the convenience yield y equal to zero, and ignore output risk altogether, then the VaR optimization problem reduces to the simpler case examined by Ahn et al (1999). Nam et al (2005) report a similar finding.

${ }_{22}$ The first-order condition with respect to $\mathrm{X}^{*}$ for each option case is available upon request.
} 
output-triggered put can hedge both (correlated) price and output risk; since the former option is more apt at hedging price risk per se, we should expect that the output-triggered put is the more effective hedging tool when price risk is low and output (usage demand) risk is high.

We would like to emphasize now that there is a rather unique advantage associated with the product offered here. If the hedger is concerned about input parameter estimation, model risk, secondary market liquidity, and the like, then it is relatively easy to tone down the exotic nature of the product and, thus, the hedge. Such tempering is accomplished by tweaking the threshold output variable, $Q^{*}{ }^{23}$ Specifically, a quick inspection of equation (7) reveals that if $\mathrm{Q}^{*}$ is set to a larger and larger value, then the product becomes more and more plain-vanilla. Indeed, by setting $\mathrm{Q}^{*}$ to infinity (which essentially represents infinite demand and the production capacity to meet that demand), the exotic option collapses to a plain-vanilla put because the output-triggering condition is moot. Thus, for those hedgers who are relatively more concerned about input parameter risk and the like, such concern can be pacified by setting a higher Q*. By setting a higher threshold output quantity the product becomes more plainvanilla, thus logically implying that the parameters associated with the exotic form of the product become less and less important in terms of valuation as well as risk metrics and management. Moreover, setting a higher $\mathrm{Q}^{*}$ should occasion more secondary market liquidity - akin to that witnessed for a plain-vanilla energy option. Another way of understanding this product property is to think of $\mathrm{Q}^{*}$ as a type of dial that the product user can turn up (at contract inception) in order to make the original contract more plain-vanilla and, therefore, less prone to model risk, exotic parameter estimation, and secondary market liquidity concerns. A trade-off, of course, is that setting a higher $\mathrm{Q}^{*}$ will serve to increase the price of the exotic towards its plain-vanilla counterpart.

\section{CONCLUSION}

This paper proposed a product that can present a cheaper and more effective revenue hedge for energy producers. The product is dubbed an output-triggered energy commodity put option. The unique feature of this option is its relatively lower cost due to its exploitation of the less than perfectly positive correlation between price and output (demand usage) that characterizes most energy product markets. Under the assumptions invoked, this paper quantified the option's price and demonstrated that this product can be more effective in minimizing a local energy provider's value-at-risk, especially when output risk (local and aggregate usage demand risk) is high. As with any exotic derivative instrument, the product's application and pricing ought to be carefully and prudently undertaken.

\section{AUTHOR INFORMATION}

Dr. Zi "Nancy" Ning is an assistant professor of finance at Delaware State University, USA. Her papers have appeared in quality finance journals including Global Finance Journal, Journal of Business Finance and Accounting, and Review of Futures Markets, etc. E-mail: zning@desu.edu (Corresponding author)

Dr. Alan L. Tucker is currently a full professor of finance at Fudan University, Shanghai, China. His papers have been published in the top-tier journals including Journal of Financial Economics, Journal of Finance, Journal of Financial and Quantitative Analysis, Review of Economics and Statistics, Virginia Tax Review, Journal of Derivatives, and Journal of Fixed Income, etc. Up to date, he has got over 50 publications. Notably, he was awarded the highly prestigious Jensen Prize in 2006, which is only granted to the best papers published in the Journal of Financial Economics. Contact author. E-mail: alantucker@fudan.edu.cn

\section{REFERENCES}

1. Ahn, D., J. Boudoukh, M. Richardson, and R. Whitelaw. (1999). “Optimal Risk Management using Options." Journal of Finance, 54, 359-375.

2. Bessembiner, H., and M. Lemmon. (2002). "Equilibrium Pricing and Optimal Hedging in Electricity Forward Markets." Journal of Finance, 57, 1347-1382.

3. Brown, G., and K. Toft. (2002). "How Firms Should Hedge.” Review of Financial Studies, 15, 1283-1324.

\footnotetext{
${ }^{23}$ Ning and Tucker (2011) make a similar observation.

(C) 2013 The Clute Institute http://www.cluteinstitute.com/
} 
4. Cartea, A., and P. Villaplana. (2008). "Spot Price Modeling and the Valuation of Electricity Forward Contracts: The Role of Demand and Capacity." Journal of Banking and Finance, 32, 2502-2519.

5. Deng, S., and S. Oren. (2006). "Electricity Derivatives and Risk Management." Energy, 31, 940-953.

6. Longstaff, F., and A. Wang. (2004). "Electricity Forward Prices: A High-Frequency Empirical Analysis." Journal of Finance, 59, 1877-1900.

7. Nam, J., A. Tucker, and J. Wei. (2005). "Price Hedging with Local and Aggregate Quantity Risk." Journal of Derivatives, 13, 49-69.

8. Ning, Z., and A. Tucker. (2011). "Hedging Import Commodity Prices for BRICS Nations." Global Finance Journal, 22, 182-190.

9. Sakong, Y., D. Hayes, and A. Hallem. (1993). "Hedging Production Risk with Options." American Journal of Agricultural Economics, 75, 408-415.

10. Schwartz, E. (1997). "The Stochastic Behavior of Commodity Prices: Implications for Valuation and Hedging." Journal of Finance, 52, 923-973.

11. Willems, B., and J. Morbee. (2010). "Market Completeness: How Options Affect Hedging and Investments in the Electricity Sector." Energy Economics, 32, 786-795. 